\title{
Anno 1529 - der „Englische Schweiß“ in Wien, die Türken um Wien
}

\author{
Heinz Flamm (D)
}

Eingegangen: 15. April 2019 / Angenommen: 12. Juni 2019 / Online publiziert: 5. August 2019

(C) Springer-Verlag GmbH Austria, ein Teil von Springer Nature 2019

Zusammenfassung Nach der Schlacht von Bosworth 1485 entstand in London eine schreckliche Epidemie des Englischen Schweißes. Bis 1551 folgten vier weitere, von denen nur jene von 1529 Mittel- und Nordeuropa erreichte. Diese bedrängte auch die Menschen im umkämpften Wien während der „Ersten Türkenbelagerung“.

Die mit Kopfschmerzen, Tachykardie und Fieber plötzlich Erkrankten produzieren stark stinkenden Schweiß. Sie werden von großer Angst, von Delirien und Schlafsucht geplagt. Die Erkrankung dauert meist nur 24 Stunden, sie kann aber auch in kürzerer Zeit zum Tode führen. Zu Anfang der Epidemien ist die Letalität besonders hoch. Die Behandlung muss sofort mit bestimmten Mitteln beginnen. Die Kranken werden durch verschiedene Methoden warm und schlaflos gehalten („Niederländisches Regiment“). Die dadurch verursachte große Todesrate konnte durch Vermeidung des Hitzestaus gesenkt werden („Englisches Regiment").

Als Ursache des Englischen Schweißes vermute ich eine wieder verschwundene „Emerging Disease“ des 15./16. Jahrhunderts, wie heute z.B. die neuen GrippeVarianten oder AIDS, Ebola und SARS.

Schlüsselwörter Englischer Schweiß . Sudor anglicus · Schweißfriesel · Wiens 1. Türkenbelagerung · Epidemie

Univ.-Prof. Dr. med. Dr. med. h.c. H. Flamm ( $₫)$ Klinisches Institut für Hygiene, Universität Wien, Wien, Österreich

Martinstraße 7, 3400 Klosterneuburg, Österreich office.martinstr@aon.at
Anno 1529 - the "English Sweating Sickness" in Vienna, the Turkish troops around Vienna

Summary After the battle of Bosworth in 1485 London was frightened by a severe epidemic of Sweating Disease. Until 1551 four more followed of which only the 1525 epidemic invaded Central and Northern Europe harassing Vienna during its "First Turkish Siege". People abruptly fell ill with headache, tachycardia, fever and secretion of stinking sweat. They were afflicted with anxiety, deliria and somnolence. The illness mostly lasted for $24 \mathrm{~h}$, but death although could occur earlier. At the beginning of epidemics the lethality was particularly high. The treatment with distinct medicaments had to be started instantly. The patients must be kept warm and sleepless ("Dutch Regiment"). The thus caused high lethality was lowered by omitting the hyperthermia ("English Regiment").

I suppose that the Sweating Disease was an "Emerging Disease" of the 15th/16th century, as nowadays AIDS, Ebola, SARS, MERS and influenza variants are.

Keywords Sweating Sickness · Sudor anglicus · Febris miliaris · Vienna's 1st Turkish Siege $\cdot$ Epidemic

Eine in meiner Bibliothek stehende Linzer Handschrift aus dem Jahre 1529 über den „Englischen Schweiß“ [1] und das heuer 490. Gedenkjahr der „Ersten Türkenbelagerung“ Wiens sind der Anlass zur Erinnerung an die Verbindung des historischen Geschehens mit dieser heute fast vergessenen Krankheit (Abb. 1).

Diese 59-seitige Handschrift trägt den Titel „Regement vnd Ártzney in dem Englisch Schwais 1529 - Vnd am lesten steet für die Breỷn - Ich noch Zü lest für die Pestilentz - Vnd noch ain blat ain köstlich bewart stückh vom Hanfsam̃en alten vnd Jungen vnd vergifften sachen“ [Breȳn, Prein, Bräun=Diphtherie; 


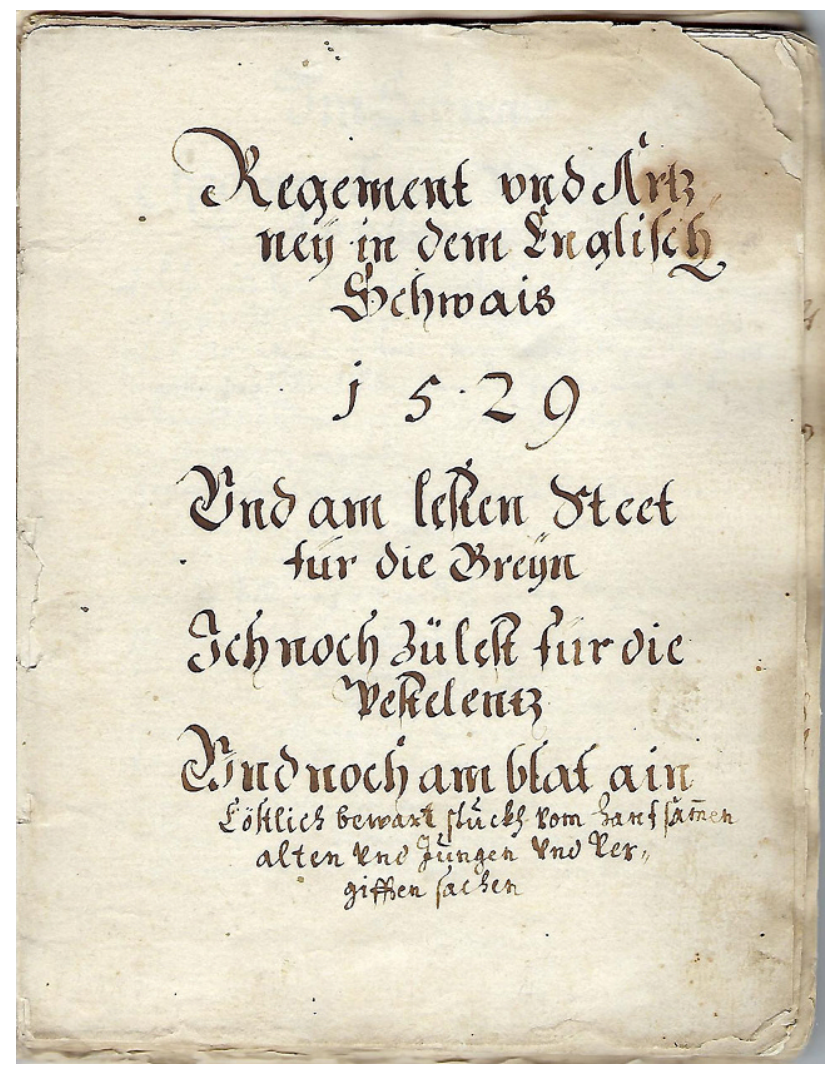

Abb. 1 Manuskript zweier Apotheker aus Linz, 1529. Titelblatt. (Aus [1])

Hanfsammen = Hanf-Samen]. Das erste Textblatt steht unter der Überschrift „Im Schwaiß - Regiment von Maister Paulsen Appotekher Zű Lintz“, in dem dieser „preseru[ $\nu]$ atim Vnd Curatim“ schreibt über das „prechen, so in Vil orthen irxtmals Vmbgeben ist“ [prechen $=$ Gebrechen, Krankheit $]$.

Der Appothekher Paul ist ebenso wie der Verfasser des weiteren Textes, der Apoteckher Dominicüs Zü Lintz, weder in Linz an der Donau noch in Linz am Rhein nachweisbar. Beide Pharmazeuten waren aber sicherlich im österreichischen Linz tätig, da Dominikus in seinem Teil „In der Pestilentz“ zweimal schrieb, dass seine Artzney auch im großen Sterben [Seuche] im Welschlandt geholfen hat [Welschland $=$ Welschtirol, Trentino $]$. Des Weiteren erwähnt er auch König Ferdinand [1521 Regent der österreichischen Erblande, 1526 König von Böhmen und Ungarn, 1531 Röm. König, 1556 als Kaiser: Ferdinand I.] .

Der „Englische Schweiß“ heißt so, denn „in dem Künigreich Engellandt ist die kranckheit anfenglich vfferstanden“ und weil „diese kranckheit schnellenglich endet“, „entweders zum leben oder todt mit eynem so vergifften übel riechenden schweiss" [2].

Der „Englische Schweiß“ oder „Sudor anglicus“ hat noch viele weitere, weniger gebräuchliche Namen wie „Schweiß-Pest“, „Pestis britannica“, „Englisches Schweyßbad“, „Ephemera britannica“ [ephemer = schnell vorübergehend], „Hydropyretus“ [Was-
ser-Hitze], „Hydronosus“ [Wasserkrankheit] und „Sudoriferus morbus“ [Schweißbringende Krankheit] [3]. Der Begründer des österreichischen Medizinalwesens und der Hygiene, Johann Peter Frank, (1745-1821) bezeichnete die Krankheit als „Schwiz-Ephemera“ [4].

\section{Die fünf Epidemien des Englischen Schweißes}

Der Englische Schweiß ist eine der verheerendsten Epidemien der beginnenden Neuzeit. Das erste dokumentierte Auftreten dieser Seuche fällt in die Zeit des Endes des englischen „Rosenkrieges“. Sie soll bereits vor der Landung Heinrichs von Richmond (Tudor) im englischen Milford Haven am 7. August 1485 in seinem in Frankreich aufgestellten Heer aufgetreten sein, das aus mit ihm 1483 geflüchteten Engländern und französischen Söldnern gebildet worden war. Nach einer anderen Meinung könnte sich aber die Truppe erst beim Marsch durch die Moore an der Waliser Grenze infiziert haben. Auf jeden Fall nahm die Seuche unter den Soldaten gewaltig zu. Sie verbreitete sich besonders, als diese sich nach dem Sieg Heinrichs über den englischen König Richard III. in der Schlacht von Bosworth am 22. August 1485 in alle Richtungen verliefen. So zog Heinrich mit nur kleinem Gefolge in London ein, wo bereits am 28. August die erste historisch festgehaltene Epidemie an Englischem Schweiß ausbrach. Sie dauerte fünf Wochen und forderte eine schreckliche Anzahl von Opfern, darunter zwei Bürgermeister und einige Ratsherren. Es wird berichtet, dass die Herren abends noch gefeiert haben und am folgenden Morgen bereits tot aufgefunden wurden [5, 6]. Wegen der fürchterlichen Ereignisse musste sogar die Krönung des Siegers zu König Henry VII. um zwei Wochen verschoben werden. Die Epidemie blieb nach den Berichten auf das eigentliche England beschränkt und griff weder auf Schottland und Irland, noch auf den Kontinent über.

Bis zur Mitte des 16. Jahrhunderts folgten noch weitere vier Epidemien, nämlich 1507 (1508?), 1516-1518, 1529/30 und 1551. Die dritte Epidemie erreichte außerhalb Englands die Nordküste Frankreichs, wo sie nur Engländer befiel und dort auch erlosch. Die vierte Epidemie der Jahre 1529 und 1530 war die schwerste. Im Juni 1529 erkrankten in London 40.000 Einwohner, von denen 2000 starben [7]. Diese Epidemie des Englischen Schweißes war nach mehrheitlicher Auffassung die einzige, die von England auf den Kontinent übertragen, sich in Mittel- und Nordeuropa ausbreitete. Den geographischen Umfang der fünf Epidemien hat Senf 1930 auf Grund von Originalquellen und Publikationen kartographisch und textlich dargestellt [8].

Den Ausbrüchen des Englischen Schweißes gingen jeweils regenreiche Jahre mit vielen Überschwemmungen und wechselnden Temperaturen voraus. Die Winter dazwischen konnten mild verlaufen. Solche Wetterverhältnisse blieben auch in den Epidemiejahren bestehen. Fast alle Epidemien begannen im Sommer. Die einzelnen lokalen Ausbrüche dauerten 
etwa ein bis zwei Wochen, manche aber auch länger. Die Epidemien erloschen meist mit Beginn der kälteren Jahreszeit.

Der Englische Schweiß war eine Krankheit des ländlichen Bereichs. In den Städten war die Ausbreitung wesentlich geringer und betraf dort die Oberschicht. Ergriffen wurden vor allem kräftige Männer mittleren Alters aus den höheren Schichten. Frauen, Kinder und alte Leute waren wenig betroffen. Die Morbidität und Letalität waren zu Anfang der fünf Epidemien sehr hoch und sanken in jeder jeweils mit ihrem zeitlichen Verlauf und ihrer örtlichen Ausbreitung.

Nach 1551 findet man den Englischen Schweiß unter diesem oder einem seiner anderen Namen nicht mehr in den Berichten über die Epidemien, die Europa heimsuchten. Nach 53 Jahren war aber die Erinnerung an die Schweiß-Krankheit offenbar noch so wach, dass Shakespeare 1604 in seinem Werk „Maß für Maß“ Krieg, Schweiß, Galgen und Armut als die Übel der Zeit bezeichnete. Aber bald verschwand die Furcht aus dem kollektiven Gedächtnis der Bevölkerungen. Heute gilt der Englische Schweiß als verschwunden und selbst seine vermeintliche milde Form, den Schweißfriesel, findet man seit einem halben Jahrhundert nicht einmal mehr in den Lehrbüchern.

Auch die epidemiologischen Überlegungen zum Englischen Schweiß waren in den 1930er-Jahren vom politischen Zeitgeist beherrscht: An der Universität Berlin führte 1937 H. Lemser aus, „daß der E.S. in seinen fünf Epidemien tatsächlich sich fast ausschließlich in von nordischer oder ganz vorwiegend nordischer Rasse besiedelten Gebieten auszubreiten scheint und nie auf die ausschließlichen Siedlungsgebiete anderer Rassen übergreift" [9]. Daher seien Frankreich und Italien frei von der Seuche geblieben. Auch die Erklärung der Ausbreitung besonders in den Flusstälern und Niederungen dadurch, dass „die nordisch-rassische Bevölkerung gerade vorwiegend ursprünglich in den größeren Flusstälern in diese Gebiete zuströmte und auch heute noch in diesen Flusstälern nachweislich stärker vertreten" sei als in anderen Landstrichen des Gebietes, entspricht dem ideologischen Zeitgeist von Lerners Publikation.

\section{Die Erkrankung}

Die klinischen Erscheinungen des Englischen Schweißes und die Maßnahmen dagegen habe ich nach den Angaben einiger Ärzte zusammengefasst, die ihre Erfahrungen in der Epidemie des Jahres 1529 schriftlich mitgeteilt haben. Es waren dies insbesondere die Originalpublikationen von Anthon Brelochs [10], Euritius Cordus [11], Caspar Kegler [12, 13], Hanns Melbrey [14], Joachim Schiller von Herderen [15] und der Gemeinschaft der Doctores zů Franckfurt, Mentz [Mainz], Worms vnd Speir [16]. Auch einige der zahlreichen Bücher und Textfragmente aus 1529 habe ich benützt, die in dem sehr umfänglichen Sammelband von Christian Gottfried Gruner (1744-1815) nach dessen Tod vom Medizinhistoriker Heinrich Haeser (1811-1884) herausgegeben wurden [17]. Auch Sekundärliteratur, die sich auf lokale Berichte bezieht, konnte Einzelheiten vermitteln [18, 19]. Alle Angaben haben kleinere Unterschiede, stimmen aber im Prinzip überein.

Die Erkrankung beginnt nach einer Inkubationszeit von 24 bis höchstens $48 \mathrm{~h}$ ohne Prodrome plötzlich mit starken Kopfschmerzen, Schwindel und Erbrechen, Schüttelfrost oder Fieber, Herzschmerzen mit Tachykardie, Hals- und Gliederschmerzen. Es kann sich Nasenbluten einstellen. Der Kranke wird schwermütig, leidet unter großer Angst und Delirien. Er verlangt nach kalter Luft, atmet sie mit großer Begierde eine. Eine starke Schlafsucht entwickelt sich. Die Kräfte des Kranken nehmen ab und er schwitzt sehr stark. Der Schweiß stinkt sehr (nach fauligen Eiern), ist gelblich und so dickflüssig, dass man ihn zwischen den Fingern aufziehen kann.

Der meist dunkle Harn wird nur in geringen Mengen produziert, so dass er für die bei den Ärzten übliche Harnschau zur Diagnose nicht reicht. Trotzdem gibt es, insbesondere von Hanns Melbrey [14], genaue Beurteilungskriterien bezüglich Farbe, Konsistenz, Inhaltsstoffen und Sediment des Harnes in Hinblick auf die Prognose des Patienten.

Die Krankheitserscheinungen sind nachts intensiver ausgeprägt.

Nur in ganz vereinzelten Fällen werden an den Gliedmaßen kleine, nicht konfluierende und die Haut sehr uneben machende Bläschen angegeben. [Wegen der später zu besprechenden Beziehung zu Schwei $\beta$ friesel wäre es gut zu wissen, ob dies tatsächlich nur Einzelbeobachtungen waren oder ob ganz einfach die Kranken nicht genau angesehen wurden, da man sie zum Schutz vor der umgebenden kalten Luft raschest zugedeckt hatte.].

Alle diese Symptome des Englischen Schweißes müssen nicht gleichzeitig und in bestimmter Reihenfolge auftreten, sie können auch einzeln oder gemischt erscheinen.

Die Erkrankung dauert im Allgemeinen 24h. Es kann aber auch der Tod innerhalb ganz weniger Stunden eintreten. Man sagte, einer steht in der Früh gesund auf, erkrankt unter tags und ist abends schon tot. In der Regel trat bald nach dem Tod eine gut erkennbare Fäulnis auf, die ein rasches Begräbnis veranlasste. Dieses sichtbare Zeichen des Todes hatte aber auch den Effekt, dass die im Volk herrschende Furcht vor dem Lebendig-begraben-werden dadurch sehr verringert wurde.

Es wurden hier also „die zeychen gemelt/durch weliche vilgemelte seucht/von den andern kranckheyten möge vnderschidlich erkenth werden“ [10]. Dies war wichtig, weil für Seuchen fast immer auch die Bezeichnung „Pest“ oder „Pestilenz" gebraucht worden ist, mit dem Englischen Schweiß aber eine für die Ärzte 
Abb. 2 Mehrere Kranke einzeln in Tücher eingewickelt und zu zweit in Betten liegend. Original nicht feststellbar. (Quelle: Gemeinfrei, Aus: https://www.welt.de/ 180675502)

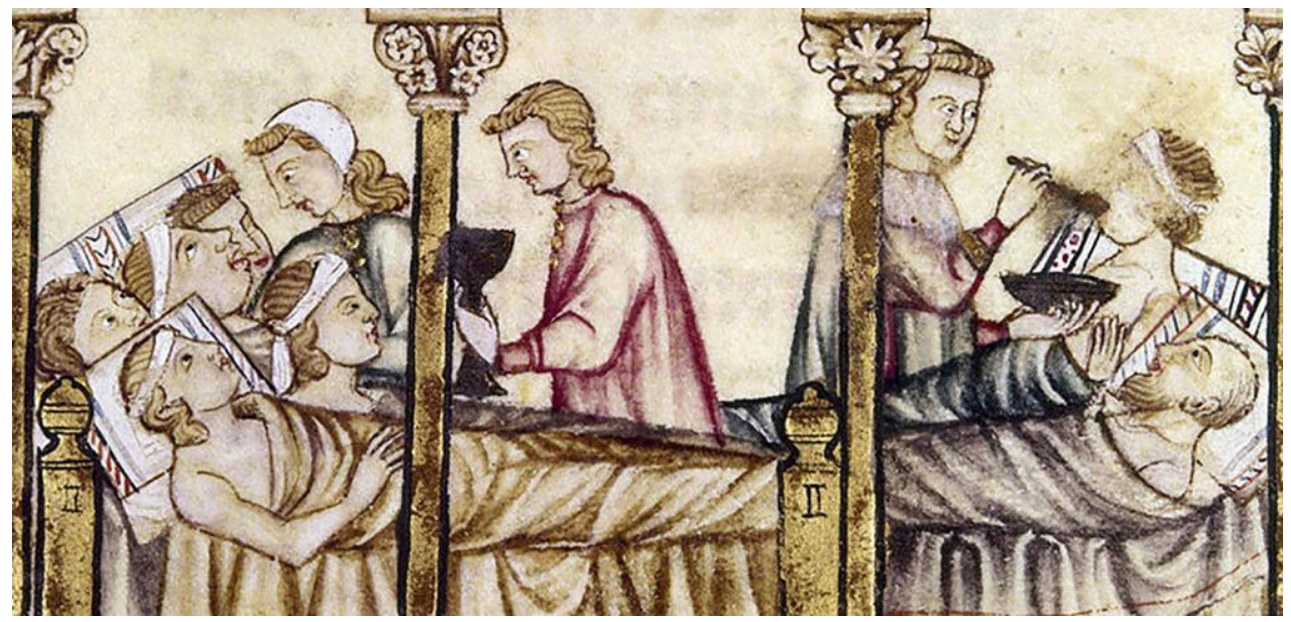

des 15. und 16. Jahrhunderts neue seuchenhaft auftretende, ebenfalls schreckliche Erkrankung zu erkennen und zu behandeln war.

\section{Die Behandlung}

Sobald ein Mensch Krankheitszeichen bietet, sind unverzüglich Pflege und Arznei notwendig. Der Arzt muss nun mit allem Fleiß feststellen, ob die Krankheit von Hitze oder Kälte ist, damit er das Widerspiel von Krankheiten benützen kann. Dem Hitzigen muss er Kühlung verschaffen, dem Kalten Wärme, dem Trockenen Feuchte und dem Feuchten Trockenheit, sodass sich die Krankheit mit den Speisen vereinigt.

Daneben bedarf der Kranke auch verschiedener Arzneien, für die es verschiedene Rezepturen gibt. So kann man z.B. ein Pulver aus verschiedenen Sirupen und bestimmten Arzneipflanzen und die gleiche Menge eines mindestens 10-12 Jahre alten Theriaks in ziemlich warmem Ampfer-Wasser zur Entfernung des „Krankheitsgiftes“ verabreichen. Gegen die Herzschmerzen kann man einen Löffel Rosenwasser mit „Herzpulver“ aus gemahlenen Korallen, Perlen oder edlen Steinen und Zucker geben. [Theriak, eine seit dem Altertum als Panazee \{Allheilmittel\} gegen viele Krankheiten gebrauchte Arznei, ist ein nach verschiedenen Rezepten hergestelltes Gemisch von ursprünglich 61 Stoffen wie Bezoar \{Magenstein von Wiederkäuern\}, Edelsteinen, Perlen, Korallen, Terra sigillata, Ambra \{wachsartiges Darmsekret des Pottwals\}, Peru-Balsam, Opium und pflanzlichen Stoffen und im Original mit getrocknetem Vipern-Fleisch [20]. Theriak war noch 1794 in der Pharmakopoea Austriaco-provincialis angeführt, allerdings nur mit fünf Bestandteilen und ohne Vipern-Fleisch [21]].

Der Kranke muss unbedingt vor kalter Luft geschützt werden, denn er soll kräftig schwitzen. Er soll also in einem warmen Raum, dessen Fenster und Türen versperrt sind, untergebracht werden. Der Kranke ist bis aufs Hemd zu entkleiden, in ein warmes Bett zu legen und mit Decken, Federbetten oder Pelzen zu bedecken. Er kann aber auch in Tücher fest eingenäht werden. Der Kopf soll in leinene Tücher eingebunden und hoch gelagert werden. Zum gegenseitigen Erwärmen kann man die Patienten auch zu zweit oder $\mathrm{zu}$ dritt gemeinsam in ein Bett legen (Abb. 2). Auch Gesunde legten sich auf Patienten, wodurch diese warm gehalten und in ihrer Bewegung gehemmt wurden. Der Kranke darf sich nämlich nur ganz wenig bewegen, damit nicht große Hitze entsteht und er nicht durch seine Unruhe kalte schädliche Luft auf sich zieht, was insbesondere für seine Füße gilt. Bei durch die Delirien verursachter Unruhe müssen ein oder zwei Männer den Kranken unter den Zudecken festhalten oder sich zur Fixierung auf ihn legen. Auch für seine Notdurft darf er nicht aufstehen. Für den Stuhl sind ihm warme Tücher unterzulegen, für das Auffangen des Harns kann man ihm Tücher oder eine warme Kachel geben.

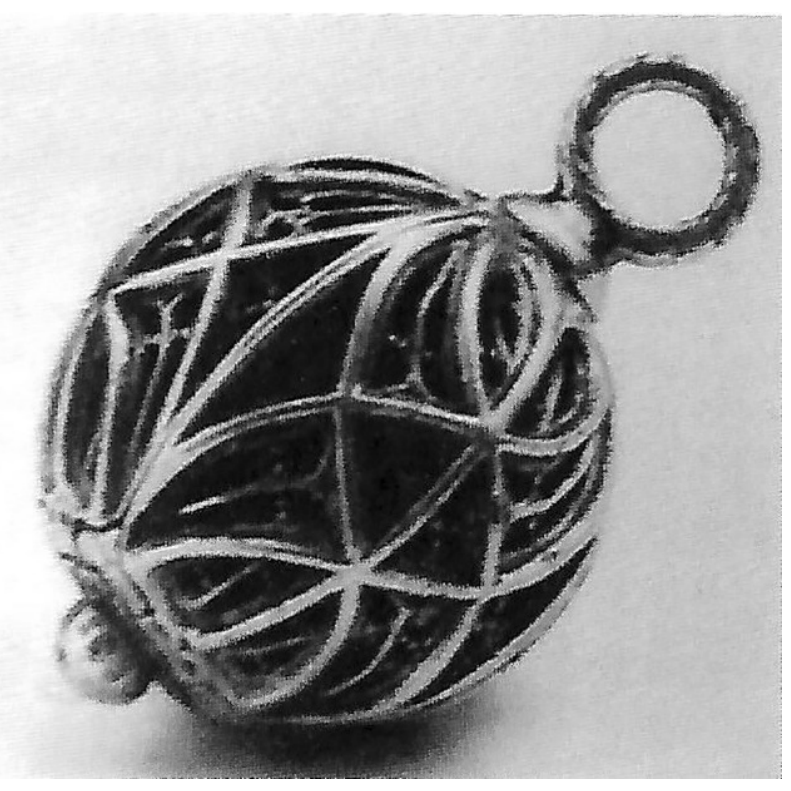

Abb. 3 Bisam-Apfel. Aus „Stadt im Wandel“. (Aus: Katalog der Landesausstellung Niedersachsen 1985). (Aus [37], mit freundlicher Genehmigung) 

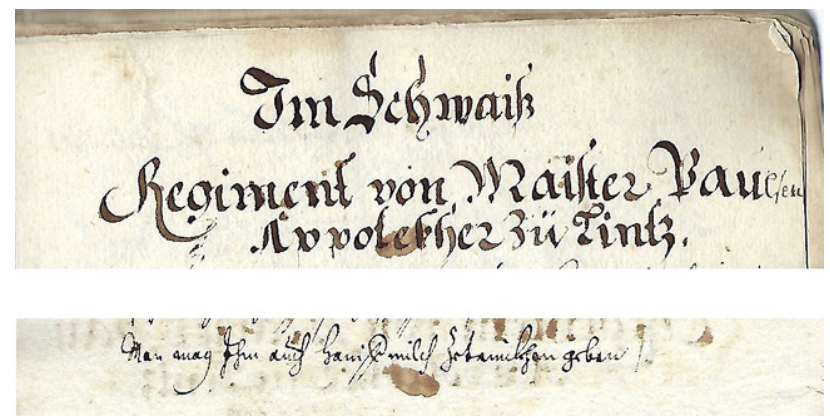

Abb. 4 Anweisung: „Man mag Ihm auch Hanffmilch Zetrinkhen geben“. (Aus [1])

Der Kranke darf zur Erhaltung der Kräfte auf keinen Fall schlafen. Deswegen bestreicht man ihm die Nasenlöcher und die Schläfen mit einem mit warmem Essig, aber auch mit Rosen-, Lavendel- oder MelissenWasser angefeuchteten Schwämmchen oder Tüchlein. Dies gilt insbesondere, wenn er den Wunsch zu schlafen hat. Zur Vermeidung des Schlafens kann man auch den bekleideten Kranken von zwei starken Männern in der warmen Stube herumführen lassen.

Auch soll er in dieser Zeit nicht essen und trinken. Und damit er nicht von Kräften falle und auch zur Milderung der gräulichen Hitze, soll man ihm von Beginn bis Ende der 24. Stunde öfter ein haselnußgroßes, nicht zu kaltes Stück von einer Latwerge aus verschiedenen Zuckerarten in den Mund halten. Dieses soll er, wenn es etwas erwärmt ist, schlucken. Der Kranke kann aber auch oft und viel von Tormentilla [Fingerkraut], Zitronenschalen, Angelica [Engelwurz], Zitwar [Kurkumawurzel] oder Diptam in den Mund nehmen, was ihn vor der Giftigkeit der Luft schützt. Auch das oftmalige Riechen an einem Ambra- oder einem Bisam-Apfel und Einatmen des ausgeströmten Duftes hilft in gleichem Sinne (Abb. 3). [Latwerge ist eine gezuckerte Marmelade, in die man verschiedene Arzneimittel mischen kann. - Bisam- und Ambra-Äpfel sind an Halsketten oder Schnüren befestigte mit einem duftenden Stoff gefüllte Anhänger. Das können einfache Nussschalen oder kunstvolle Geschmeide sein. - Bisam ist das stark riechende Sekret der Moschusdrüse des Moschus-Hirschens.]

So der Kranke zur Erhaltung seiner Kräfte doch essen und trinken will, kann er ziemlich warme Hühneroder Fleischbrühe und etwas Wein oder Ampfer-Wasser zu sich nehmen.

Einzig nach dem Regiment des Appotekhers Maister Paul von Linz an der Donau wird dem Kranken alle Morgen nüchtern ein Trunk Hanfmilch verabreicht [1]. Die Erwähnung des Hanfsamens auf dem Titelblatt der Handschrift soll vielleicht auf die Besonderheit der Behandlung nach dem Linzer Regiment hinweisen. Bei keiner Therapie-Empfehlung eines anderen Autors habe ich den Hanf gefunden (Abb. 4).

Es wird empfohlen, das Zimmer des Kranken mit wohlriechenden Stoffen zu räuchern, wie z. B. Räu- cherkerzen, Zitwar, Gewürznelken, Mastix, Myrrhe oder Weihrauch.

Wenn der Kranke das Schwitzen überstanden hat, soll man anfangen, ihn ganz sanft an allen Gliedern mit ziemlich warmen Tüchern abzutrocknen, dies insbesondere hinter den Ohren, unter den Achseln, zwischen den Beinen und an den Fußsohlen. Danach soll man ihm helfen, in ein anderes warmes Bett zu kommen, wo er essen und trinken mag.

Später darf sich der Kranke zum Feuer setzen. Er soll Arme, Beine und Fußsohlen mit warmen Tüchern zur Anregung seiner Natur und Erleichterung des Herzens reiben. Er muss sich überhaupt die nächsten Tage warm und trocken halten, bis sich seine Natur und sein Wesen ganz erholt haben. Weiters soll er beim Essen und Trinken mäßig bleiben. Nachdem er sich erholt haben wird, soll er purgieren und sich von einem Arzt zur Ader lassen. Dies wird ihn vor der Wiederholung derselben Seuche bewaren, die stets ärger ausfallen würde. Die Rekonvaleszenz dauert etwa eine Woche, nach welcher die meisten Kranken wiederhergestellt sind. In manchen Fällen bleiben aber über Jahre Herzklopfen und Gliederzittern bestehen. Auch wiederholtes Auftreten der Erkrankung ist, wenn auch selten, möglich.

Diese geschilderten Maßnahmen des gewaltsam erzwungenen starken Schwitzens wurden als „Niederländisches Regiment“ bezeichnet. Sie verursachten sehr hohe Todesraten von bis $\mathrm{zu} 90 \%$ der so Behandelten. Man kam jedoch nicht nur in England, sondern auch vieler Orts zur Erkenntnis, dass man sich bemühen muss, Fieber und Schwitzen auf 6 bis $8 \mathrm{~h}$ zu begrenzen. Die Maßnahmen dieses sogenannten „Englischen Regiments“ beschreiben genau Hanns Melbrey in Speyer [14] und ein ungenannter

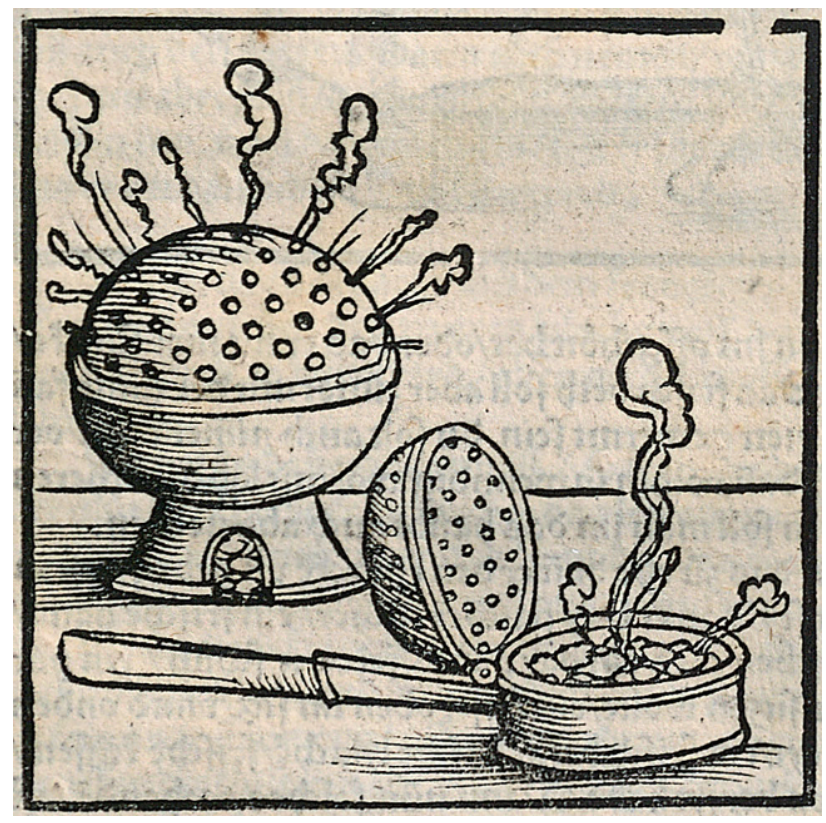

Abb. 5 „glůt oder bethpfañe“ zum Trocknen der verschwitzten Tücher und zum Wärmen von Bett und Kranken. (Aus [14]) 
Abb. 6 Begrenzter Luftraum über dem Kranken. (Aus [14])

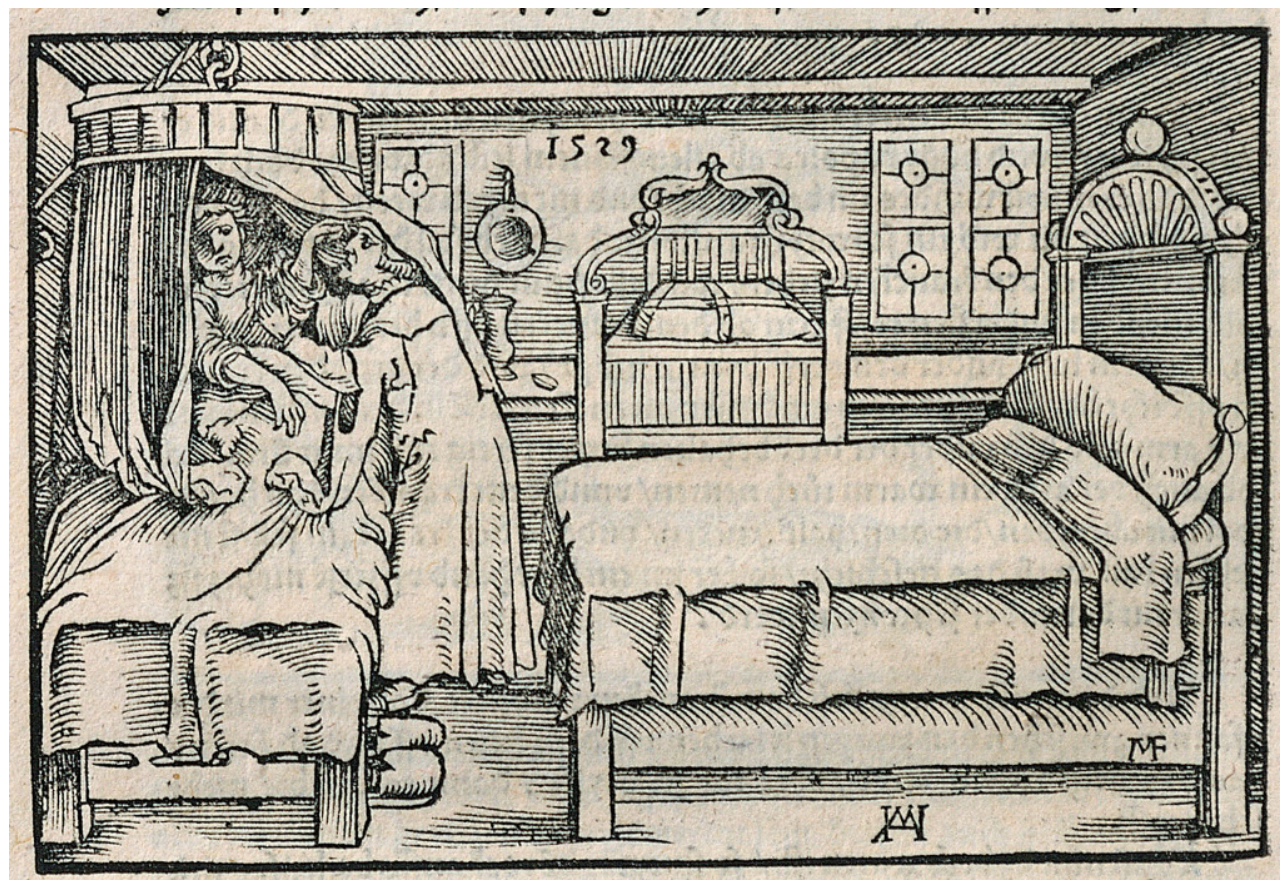

süddeutscher Autor [22]. Dabei ist es wichtig, die Kranken nur so locker, ohne Federdecken oder Pelze zuzudecken oder einzunähen, dass „der gestanck vom schweyß/vnnd die wind vnd die vergifften vapores“ entweichen können. Die Decken sollen bei den Beinen so locker sein, dass man für den Stuhlgang ein Becken hineinschieben kann. Die ganz schweißnassen Leintücher und die Tücher zum Abtrocknen von Stirn und Kopf müssen gewechselt werden. Zum Trocknen eignen sich irdene oder kupferne „glůt oder bethpfañen“, durch deren perforierten Oberteil Hitze an darauf gelegte Tücher oder in die Umgebung abgegeben wird (Abb. 5). Sie werden auch zum Vorwärmen eines frisch überzogenen Bettes und des Hemdes des Kranken verwendet. Auch den Kranken kann man damit wärmen. Im Bett sitzend wird er mit Hemd und Rock bekleidet. Zum Erwärmen der ihn umgebenden Luft mit einer Bettpfanne wird der Luftraum durch ein Leintuch begrenzt. Dazu wird rund um den Kranken ein ringförmiges Gestell gelegt. Rund herum wird ein Leintuch angenäht. Das Gestell wird danach mit einer Schnur über einen an der Raumdecke befestigten Haken in die Höhe gezogen, sodass über dem Kopf und eventuell auch dem Oberkörper ein abgeschlossener Luftraum entsteht (Abb. 6).

Wenn der Kranke aus Hunger essen will, kann er lauwarme Gerstenbrühe bekommen. Trinken darf er Gerstenwasser, dünnes Bier und Molken, aber stets nur lauwarm. Wasser, Wein und Brandwein haben sich nicht bewährt.

Dieses „Englische Regiment“ verringerte die Letalität gewaltig, diese lag sogar unter der von Pest und Pocken.

\section{Die Prophylaxe}

Das ist ein „Regimen preseruatiuum, wie sich eyn ieder mensch dar in schick, das er fürkome vnd abwende diss vergifft böss fieber, das durch solchen schnellen, grossen vnnd stinckendenn schweyss seyn end nymt“ [2]. Es ist also wichtig zu wissen, „wie sich ein jglicher Mensch/wasserley Complexion er ist/das gantze Jar über præseruiren vnd bewaren kann/das er mit Göttlicher hülff vnd gnade nicht inficirt werde von einerley Gifft" [12].

Die Antwort in jener Zeit war, dass sich der Mensch in seiner Lebensführung an die seit alters her gültigen „Sex res necessariæ non naturales“ [23] haltet. Man findet diese in unserem Bereich in den umfänglichen Werken des Tirolers Hippolyt Guarinoni (1610) [24] und des Oberösterreichers Johann Kaspar Heyrenbach (1753) [23].

Die „sechs unvermeidlichen und nebennatürlichen Sachen" sind: Aer (taugliche Luft), Nutritio = Cibus \& Potus (essen \& trinken), Tempus = Motus \& Quies (körperliche Bewegung \& Ruhe), Vigiliæ \& Somnus (Wachsein \& Schlaf), Inanitio = Excernenda \& Retinenda (Ausscheidung \& Aufnahme), Animi Passiones (Gemütsbewegungen) [23, 24]. Mehr oder weniger ausführliche Anweisungen für die Vermeidung des Fangens des Englischen Schweißes findet man in vielen Publikationen. Eine der genauesten gab Schiller von Herderen [15].

Gegen die Giftigkeit der Luft sollen die Räume geräuchert werden. Der Einzelne kann sich auch dadurch schützen, dass er oft und viel von Tormentilla [Fingerkraut], Zitronenschalen, Angelica [Engelwurz], Zitwar, Bibernell, Diptam, Baldrianwurzel oder Stückchen von Einhorn [Narwal-Zahn] und noch manches 
andere in den Mund nimmt. Auch das oftmalige Riechen an einem Bisam- oder Ambra-Apfel hilft in gleichem Sinne. Für das gemeine Volk und die Dienstboten eignet sich im Frühling und Sommer das Riechen an einem Schwämmchen, das mit etwas Essig und Kampfer enthaltendem Rosenwasser befeuchtet ist. In der kalten Jahreszeit sollen sie stattdessen starken Wein mit Melissen oder auch Wasser mit Zimt oder Gewürznelken verwenden.

Da man die Ursache aller Erscheinungen des Englischen Schweißes als Folge zu vieler „feuchtigkeyt“ im Blut und überhaupt im Körper annahm, stand bei den Regeln für die Ernährung an erster Stelle die Vermeidung überflüssigen Trinkens, wie auch empfohlen wurde, beim Essen mäßig zu bleiben. Dies gilt insbesondere für Früchte, Fische, Krebse, Milch, Honig, Met und Wein, Hirn, Schweinefleisch, Gekröse und Köpfe. Von Geflügel seien solche Vögel erlaubt, die nicht im Wasser leben, wie ja überhaupt Speisen zu meiden sind, die zusätzliche Feuchtigkeit an den Körper abgeben. Es ist also besser gar keine Früchte zu essen. Als gut gelten Essig, Eier und Fische mit hartem Fleisch, schwacher Rot- und Weißwein und dünnes Bier.

Hierher gehört auch die Remedia Preservativa der Doktorengemeinschaft aus Frankfurt, Mentz, Worms und Speyer [16]. Eine ausgehöhlte Zwiebel ist mit einem guten Theriak zu füllen und weich $\mathrm{zu}$ braten; diese isst man abends ohne anderes Essen und Trinken und legt sich fest zugedeckt ins Bett, worauf man stark schwitzt.

Körperliche Betätigungen soll man nicht übertreiben. Der Übergang von Tätigkeit in Ruhe und umgekehrt darf nicht abrupt erfolgen. Arbeit ist besser als Müßiggang und soll in guter Luft verrichtet werden.

Man darf nicht den Modus von Schlafen in der Nacht und Wachen am Tag missachten, den uns jeweils unsere eigene Natur vorgibt. Eine Änderung der Zeiten ist schlecht, wie Beispiele oft zeigen. Aber auch $\mathrm{zu}$ langes Schlafen ist ebenso schlecht wie $\mathrm{zu}$ langes Wachbleiben.

Im Überfluss vorhandene Stoffe scheidet der Körper aus. Dazu gehören Stuhl, Harn, Erbrochenes, Speichel, Rotz, Schleim, Gallen, Menstrual-Blut, dickes Blut in den Adern, Schweiß, Haare und Nägel. Aus der Vernachlässigung solcher Überflüsse kann Krankheit entstehen.

Das Gemüt ist des Menschen zweiter Teil neben dem Körper. Die Gesundheit bedarf einer guten Beschaffenheit des Gemüts. Zu dessen Übung soll man sich von Zorn, Unmut, Sorglosigkeit und Todesfurcht fernhalten.

Guarinoni hat, wie er schreibt, als Erster den sechs nebennatürlichen Sachen eine siebente vorangestellt: Gott [24]. Die Einhaltung der göttlichen Gebote ist für die Verhütung jeder Seuche besonders wichtig, steht doch an prominenter Stelle der Krankheitsursachen der Zorn Gottes.

Wie schon bei der Ernährung gesagt, ist es ganz wichtig, möglichst wenig zusätzliche Feuchtigkeiten aufzunehmen. Zu bestimmten Zeiten ist der Körper von bösen Feuchtigkeiten zu befreien. Durch Aderlassen gelingt dies aus dem Blut und die nicht mit diesem vermengten Feuchtigkeiten wie Gallen, Wasser oder Schleim können durch Purgieren ausgetrieben werden. Damit die entfernten Feuchtigkeiten im Körper nicht erneuert werden, nimmt man verschieden starke „Pestilentz pillulen“ nach ärztlichem Rezept. Für diese „Ertzneyen“ bekommt der „Apotecker“ genaue Anweisungen für den Sommer und für den Winter. Diese Pillen enthalten eine große Zahl verschiedener pflanzlicher Bestandteile, aber auch gemahlene Edelsteine wie Saphir, Smaragd und Rubin. Schiller von Herderen gibt eine große Zahl von einfachen und von zusammengesetzten Präservantien an [15].

Der Apoteckher Dominicus in Linz an der Donau nennt als „ain bewerte Versiecherung“ in Zeiten, „so die schräckhlich plag regirt“, dass „alle Morgen nüchtern ein Trunckh Hanif milch [Hanfmilch] gethan“ wird [1].

Ist schon um einen herum die Seuche ausgebrochen, so muss man beachten, dass auch vom Kranken selbst und von allem, das mit ihm Kontakt gehabt hat, die Krankheit weitergegeben werden kann. Der Apoteckher Dominicus warnt, „Wan der Kranckh schwizt, soll man sich hüthen Von seinem aden [Atem] Vnd dem dampff so Von Ihm gehet, damit niemandt Vergiffs [vergiftet] wird, man sol auch das Peth [Bett-] Vnd Pathgewandt [Bade-, Reisegewand] schön waschen Vnd lang erlüfften lassen“ [1]. Das würden wir heute als Vorbeugung der direkten und indirekten Infektion bezeichnen.

\section{Die Epidemie von 1529/30 und die „Erste Türken- belagerung Wiens"}

Die vierte Epidemie des Englischen Schweißes begann Ende Mai 1529 in den dicht bewohnten Vierteln Londons, von wo sie ganz England, jedoch nicht Schottland und Irland erfasste. Am 25. Juli 1529 wurde die Erkrankung durch ein namentlich bekanntes Schiff nach Hamburg übertragen. Dort traten bis 15. August täglich 40 bis 60 , insgesamt etwa 1100 Todesfälle auf, was 6-9\% der Gesamteinwohnerzahl entsprochen haben soll. Von Hamburg breitete sich die Seuche rasch aus. Im Osten und Norden erreichte sie am 8. September Königsberg und zu Ende desselben Monats auch Dänemark und Schweden. Heinz Zeiss (1888-1949) widerlegte die Behauptung des Vorkommens des Englischen Schweißes in Russland und stellte auf Grund von Mitteilungen und des Aktenstudiums fest, dass diese Seuche im Raum zwischen dem $25^{\circ}$ und $30^{\circ}$ östl. Länge erloschen ist [25].

Im Westen wurden im September und Oktober 1529 die Niederlande betroffen. Nach Süden ergriff die Seuche ganz Deutschland. Bayern und Österreich erreichte sie im September und im Südwesten entlang des Rheins im Dezember Bern. Es wurde festgestellt, dass die Seuche milder wurde je später ein Ort betroffen 
war und somit im Allgemeinen auch bei ihrem Fortschreiten nach Südwesten und Süden. So starben beispielsweise in Dortmund ab 3. September 497 von 500 Erkrankten und in Augsburg ab 1. September innerhalb von 11 Tagen 800 der 15.000 Kranken, während es in Stuttgart im folgenden Monat nur mehr 6 von 4000 waren. Die letzten Berichte über das Auftreten der Seuche stammen von 1530 aus Oberösterreich und Finnland.

Die Ausbreitung der Seuche im Jahr 1529 mit den Anfangsdaten in wichtigen Städten Mittel- und Nordeuropas hat Harry Kühnel (1927-1995), der erste Direktor des ÖAW-Instituts für Realienkunde des Mittelalters und der frühen Neuzeit in Krems an der Donau, auf Grund der in der umfänglichen Literatur festgehaltenen Daten in einer Landkarte sehr übersichtlich dargestellt [26].

In die Religionsgeschichte Deutschlands hat der Englische Schweiß insofern eingegriffen, als das am 3. Oktober 1529 begonnene „Marburger Religionsgespräch“ aus Furcht vor der Krankheit bereits nach drei Tagen ohne Einigung abgebrochen wurde und Luther, Zwingli und die beteiligten Fürsten die Stadt verließen [27]. Damals waren in Marburg etwa 50 Menschen am Englischen Schweiß erkrankt, von denen ein bis zwei starben. Auch Wittenberg war von dieser Krankheit betroffen. Um diese Zeit trat in beiden Städten außerdem die Pest auf.

Für das Gebiet der heutigen Republik Österreich ist der Nachweis des Englischen Schweißes dürftig. In keinem der von mir befragten neun Landesarchive finden sich Anmerkungen über den Englischen Schweiß. Wahrscheinlich hat sich aber die Seuche in allen Habsburgischen Ländern nördlich der Alpen und im damals selbständigen Fürstlichen Erzbistum Salzburg ausgebreitet. Unabhängig davon könnte jedoch die Infektion auch auf kurzem Wege durch 30 Frankfurter Bürger eingeschleppt worden sein, die zur Verstärkung der Besatzung in die befestigte Stadt Wien abkommandiert worden waren.

Einen zeitgenössischen Bericht über den Englischen Schweiß in Österreich gibt es nur aus Österreich ob der Enns. Aus einem brieflichen Verkehr zwischen König Ferdinand und seiner im Linzer Schloss weilenden Schwester Maria [Witwe des 1526 in der Schlacht bei Mohács gefallenen ungar. Königs Ludwig II.] ist ersichtlich, dass die Seuche nach einem zeitlichen Rückgang bis Ende Feber 1530, dann während eines herrschenden Regenwetters wieder stärker geworden, am 9. März 1530 in Oberösterreich endlich erloschen ist [18].

Für Wien gibt es schriftliche Hinweise auf die Seuche von 1529 nur aus dem 18. Jahrhundert. So schrieb der Einsiedler-Mönch Mathias Fuhrmann 1739 in seiner Beschreibung der Kayserlich- und ErtzLands-Fürstlichen Residenz-Stadt, das Jahr 1529 war „gewißlich eines der denckwürdigsten und betrübtesten/so unser Wien erlebet/inmassen erstens ein böse und vorhin nie erhörte Seuche hieselbst regie- ret/insgemein dy Schwais-Sucht genannt/welche ... wie die Pestilentz selbst/viel tausend/auch in unserm Wien hingerissen/und zwar um desto fataler/weil ein Mensch in einem Tag gesund/kranck/und todt gewesen“ [28]. Auch der Melker Benediktiner-Mönch Hieronymus Pez [29] und der Wiener PhilosophieProfessor Sebastian Mitterdorffer, SJ [30] erwähnten in ihren Schriften 1721 bzw. 1724 den Englischen Schweiß in der Wiener Bevölkerung.

Sicherlich hatte der Englische Schweiß für die Bevölkerung und für die Besatzung des befestigten Wiens eine sehr große Bedeutung. Denn während dieser „Ersten Türkenbelagerung“ hatte „Wien ein hartes auszustehen von Solimanno dem Groß-Türckischen Sultan, welcher mit einer Armée, biß 30.000 [oder 120.000] Mann starck, in Oesterreich eingefallen, diese Stadt härtiglich belägert, und in die äusserste Aengsten gebracht“ [28]. Die Belagerung begann bei schlechtem Wetter am 21. September um 9 Uhr. Nach vier erfolglosen Stürmen gegen die befestigte Stadt begann Suleiman am 15. Oktober bei dauerndem Schneefall den Abzug des osmanischen Heeres, der am 18. Oktober beendet war.

Die deutschen Medizinhistoriker des 19. Jahrhunderts Heinrich Haeser (1811-1884) [31], Justus Friedrich Carl Hecker (1795-1850) [6, 32], August Hirsch (1817-1894) [33] und Friedrich Schnurrer (1784-1833) [34] legten die drei oben genannten Autoren [28-30] etwas extensiver aus. Sie meinten, die Stürme der Türken wurden mit rühmlicher Tapferkeit abgeschlagen, sodass Sulaiman die Belagerung beendete, „nachdem der englische Schweiss nicht weniger unter seinen Schaaren gewüthet hatte als unter den Belagerten. Genauere Nachrichten hierüber fehlen, weil man bei viel grösserer Bedrängniss des Landes auf die Seuche weniger achtete, doch war die Sterblichkeit in Oesterreich unter so ungünstigen Umständen wohl bedeutender als in den Nachbarländern“.

Diese Meinung, dass die Türken ebenfalls vom Englischen Schweiß befallen waren, findet sich auch in einer norddeutschen Schrift. Nicolaus ab Klempzen schrieb 1771, dass „Solimann, der Türkische Kaiser“, Wien belagerte. „Da kam der Schweiss unter sein Volk, dass er die Länge musste wegziehen“ [35].

Wenn der Englische Schweiß tatsächlich auch die türkischen Truppen befallen hat, so muss die Belagerung wohl nicht nur deswegen abgebrochen worden sein. Während der Belagerung herrschte ein schlechtes und kaltes Wetter. Es ist also sicher anzunehmen, dass zu den üblichen Lagerseuchen auch respiratorische Infektionen häufig die in Zelten lagernden Truppen befallen haben. Abgesehen von den gesundheitlichen Beeinträchtigungen der Soldaten hatte Sulaiman einen militärischen Mangel. Er konnte mit seinen vorhandenen Kräften die Wiener Mauern nur an einer Stelle kurzzeitig durchbrechen, da er wegen der durch das Wetter unwegsamen Straßen seine schwere Artillerie in Komorn [Komárno (slowak.), Komárom (ungar.)] zurückgelassen hatte und sie wegen der kai- 
serlichen Truppen in Preßburg [Bratislava (slowak.), Pozsony [ungar.] auch nicht auf der Donau nach Wien bringen konnte.

Ob andere Habsburgische Kronländer von der Seuche verschont geblieben sind, ist mir nicht bekannt. Sicher war der 1529 frühzeitig einbrechende Winter von epidemiologischer Bedeutung. So hält man die dadurch entstandene Unterbrechung des Verkehrs über die Alpen, zumal damals keine ausgebauten Straßen bestanden, als Ursache des Endes des Seuchenzuges nördlich des Gebirges. Der Winter wird wohl auch das Übertreten des Englischen Schweißes über die Sudeten, Beskiden und Karpaten nach Böhmen, Mähren und Oberungarn (Slowakei) verhindert haben. Aus dem Semmelweis-Museum und Archiv in Budapest habe ich die Mitteilung, dass keine Angaben über das Vorkommen des Englischen Schweißes in Ungarn des 16. Jahrhunderts vorliegen.

\section{Die Ursachen des Englischen Schweißes}

Die Entstehung von Seuchen beschäftigte die Menschen schon im Altertum. In den Zeiten von Epidemien, insbesondere der Pest, war dieses Interesse besonders groß. An erster Stelle stehen Gottes Zorn und Strafe wegen der Sünden der Menschen. Auch der irdische Himmel bietet viele vermeintliche Krankheitsursachen, nämlich das Auftreten von Kometen, Mond- und Sonnenfinsternissen. Wichtig erschien auch der Einfluss [Influenza, sic!!!! der Sterne durch ihre Konstellationen [Con-Stellae, sic.]. Auf der Erde selbst fürchtete man Erdbeben, Heuschreckenplagen, Tierseuchen, große Hitzeperioden mit Dürren und enorme Niederschläge mit Überschwemmungen und ganz allgemein die „giftige Luft“. Letztere wirkte durch Einatmen direkt auf den Körper und indirekt, indem sie als Tau und Nebel Früchte für den Menschen und Weidegründe für das Vieh vergiftete, was letztlich auch die menschliche Ernährung betrifft. Vielen der Naturereignisse folgten Hunger, Teuerung und Verarmung [36].

Vom Englischen Schweiß hatten von der ersten Epidemie angefangen etliche Autoren berichtet, dass in Britannien nur Engländer, nicht aber Schotten, Iren und Ausländer vom Englischen Schweiß ergriffen worden sind. Diese Krankheit folgte den Engländern auch ins Ausland, sodass diese in den Niederlanden, in Frankreich und sogar in Spanien von der Seuche erreicht wurden $[6,8]$. Daher nahm Hecker, noch in der vorbakteriologischen Zeit, an, es gäbe „irgendeine Eigenthümlichkeit in dem ganzen Sein der Engländer, welche ausschließlich sie für diese Krankheit empfänglich machte“. Dieser Meinung waren auch schon die Zeitgenossen der Epidemien, die Völlerei und rohe Lebensweise der Engländer als die Voraussetzungen der Krankheit ansahen, „die ohne Zweifel auch ihres Theils den Deutschen und Niederländern im Jahre 1529 dieselbe Geissel zugezogen haben“ [6]. John Kaye (=Johannes Caius, 1510-1573), der Leibarzt von
Edward VI., berichtete seine eigenen Erfahrungen in der Epidemie von 1551, dass nämlich auch in England die Mäßigen von der Schweißsucht verschont geblieben seien [37]. Diese „Eigentümlichkeiten“ sollten wohl nur die Voraussetzung dafür sein, dass der Englische Schweiß entstehen kann.

Für das böse verlaufende Jahr 1529 hatte man beängstigende Vorzeichen beobachtet. Am Sternenhimmel sahen die Menschen gleichzeitig vier Kometen, deren Schweife in die vier Himmelsrichtungen wiesen. Aber darüber hinaus gab es noch weitere beunruhigende Ereignisse. Vieler Orts starben Vögel, unter deren Flügeln erbsengroße Abszesse zu sehen waren. Gleichzeitig herrschte auch eine Seuche unter Schweinen, der sehr viele erlagen [15]. Auch die Wetterphänomene waren unheilkündend. So war die dem milden Winter 1528/29 folgende Zeit bis in den Spätsommer geprägt durch starke Niederschläge mit vielen Überschwemmungen, dann kamen trübe und nasskalte Monate bis zum frühen Wintereinbruch [19]. Diese Witterung führte zu ganz schlechten Ernten von Getreide und Wein. Eine siebenjährige Teuerung und Hungersnöte waren die Folge. Nach einem Bericht wurde sogar das Brot aus Eicheln hergestellt [19]. Der wenige Wein war schlecht und sauer, er wurde wegen des bereits vorhersehbaren türkischen Angriffs auf Wien abwertend „Türkenwein“ genannt [38].

Anthonius Klump aus Überlingen am Bodensee hat, entsprechend der damaligen Vorstellung, die Entstehung des Englischen Schweißes 1529 beschrieben [2]. Es sei nämlich „ein vrsach dieser kranckheit eyn verborgene neigung des gestirns vnd der planeten, dieselbigen mit etlichen influss die sie habent in die körpel harnider, bringen sie anzündung in das blut, vnd wie sie findent ein gross inordinantz in den feuchtigkeiten des gantzen leibs viler menschen, wirt als dan verursachet ein putrifaction vnd heimliche feule [Fäulnis], von wölicher kompt dan ein gifft, dassebige gifft zint [zündet] an, wirt daruss solchs pestilentzis fieber“. Dass dies wahr ist, „magsttu befinden vnd augenscheinlich ermessen an dem stinckenden schweyss, sodann bey etlichen erfunden wirt, die dieser kranckheit vnderwirflich gewesen sind vnd werdent".

Unter den naturwissenschaftlichen Vorstellungen des beginnenden 19. Jahrhunderts, aber noch in der vorbakteriologischen Ära wies Gruner 1804 in seinem Kommentar zur Natur des Englischen Schweißes auf die Ähnlichkeit seiner Symptome mit jenen des Febris miliaris und der damals häufigen Influenza [17].

Die Geschichte des Febris miliaris [Milium= Hirsekorn] beginnt nach einer Pause vom Ende der fünften Epidemie des Englischen Schweißes (1551) bis zum Sommer 1718 als über eine „neue“ Krankheit in der Pikardie (Nordfrankreich) berichtet wurde, die durch starkes Schwitzen, nervöse Beeinträchtigungen und Frieselbildung auffiel („Suette des Picards“). Nach deren Ausbreitung als Volksseuche in Frankreich wur- 


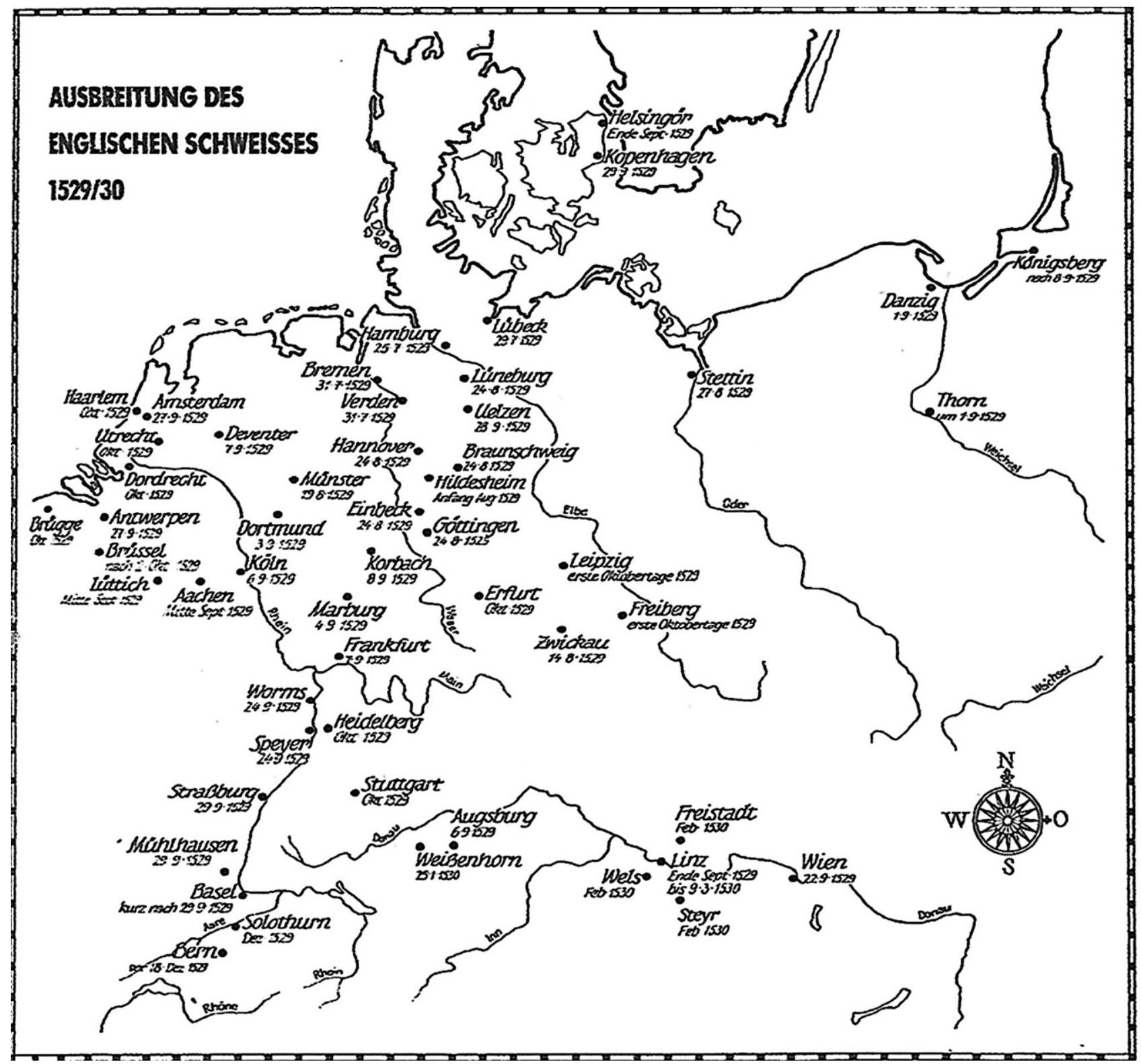

Abb. 7 Ausbreitung des Englischen Schweißes 1529/30. (@ Atelier Proidl aus [26]. Mit freundlicher Genehmigung von Sylvie Proidl)

de die Bezeichnung „Suette miliaire“ gebräuchlich. Der dafür verwendete deutsche Namen „Schweißfriesel“ lässt sich von freisa (ahd.), vreise (mhd.) = Unheil, Verderben oder von vriesen (mhd.) = frieren ableiten; im 16. Jahrhundert bedeuteten Fräsel und Fraisel allgemein eine schwere Krankheit.

Wegen der häufig diskutierten Meinung, der Schweißfriesel sei eine abgeschwächte Form des Englischen Schweißes, sei er hier etwas ausgeführt.

Der Schweißfriesel breitete sich von Frankreich in Italien, Deutschland und Belgien aus. Auch in Österreich und angrenzenden Ländern der Monarchie gab es bis zum Ersten Weltkrieg zum Teil schwere Schweißfriesel-Epidemien wie z.B. 1835 \& 1913 in der Steiermark, 1836 in Oberösterreich, 1859 in Ybbs,
1873/74, 1878, 1892 und 1905 in der Krain, 1893 im Ausseer-Land und 1896/97 im Bezirk Scheibbs.

Der bekannte Wiener Pathologe Anton Weichselbaum (1845-1920) beschrieb auf Grund seiner praktischen Erfahrungen bei drei Epidemien die Epidemiologie und die pathologischen Befunde [39]. Er stellte fest, dass „der Schweißfriesel eine Krankheit sui generis ist" und nicht nur ein Symptom bei verschiedenen Krankheitsbildern.

Der Schweißfriesel erschien plötzlich und fast gleichzeitig in kleinen Orten und Einzelgehöften eines fast immer ländlichen Gebietes, jedoch ohne Tendenz $\mathrm{zu}$ einer größeren räumlichen Ausbreitung. Die Erkrankungen waren nicht auf Sommer und Herbst beschränkt. Sie befielen meist gesunde und kräftige Menschen mittleren Alters. Besonders empfänglich 
waren Frauen im Wochenbett und während der Menstruation. Einzelne Epidemien betrafen vornehmlich Kinder.

Der Schweißfriesel begann nach einer Inkubationszeit von 1-2 Tagen plötzlich mit hohem Fieber und starkem Schweißausbruch. Meist endete dieser nach 3-6h, er konnte sich nach einigen Stunden wiederholen oder überhaupt ohne Pause mehrere Tage anhalten. Da sich der Schweiß in der Leib- und Bettwäsche rasch zersetzte, verbreitete sich ein unangenehmer Geruch. Die Kranken hatten ein Frostgefühl und fürchteten den geringsten Luftzug. Es entstanden nervöse Erscheinungen wie entzetzliche Angst, Benommenheit, Delirien und Konvulsionen. Der Tod konnte noch vor der Entwicklung des Exanthems plötzlich eintreten. Dieses entstand am dritten oder vierten Krankheitstag als hirsekorngroße Knötchen, die nach wenigen Stunden zu gleich großen Bläschen wurden. Die Krankheitszeichen verringerten sich im Verlauf weniger Tage [40].

Offenbar verschwand der Schweißfriesel in der ersten Hälfte des 20. Jahrhunderts und man sucht ihn in den Lehrbüchern der Infektionskrankheiten und der Kinderheilkunde danach vergeblich. Nach dem Krankheitsbild und der Epidemiologie zu schließen, scheint mir der Schweißfriesel nicht eine Fortsetzung oder ein Wiederauftreten des Englischen Schweißes zu sein.

Zurück zur weiteren Besprechung der vermuteten Ursachen des Englischen Schweißes, den man im 20. Jahrhundert fast einstimmig für eine Infektionskrankheit hielt. Es gab aber auch Autoren, die eher an Vergiftungen wie Lebensmittelvergiftung, Botulismus oder Ergotismus glaubten. Die Begründungen und Gegenargumente wurden von Patrick und Roberts diskutiert [41]. Man kann sich tatsächlich nicht vorstellen, wie Vergiftungen entsprechend der bekannte zeitlichen Ausbreitung des Englischen Schweißes (Abb. 7) entstehen könnten.

Einige Untersucher konzentrierten sich beim Studium der Literatur des 16. Jahrhunderts auf verschiedene mehr oder weniger betonte Symptome für ihre Erklärung der Ätiologie des Sudor anglicus. So wurden Grippe, Q-Fieber, Rückfallfieber, Lungenmilzbrand, Encephalitis lethargica, Encephalitis japonica und zuletzt Hantavirus-Infektion als Ursachen genannt.

Bei Überlegung der Epidemiologie und des klinischen Bildes der angeführten Infektionen kann man wohl Q-Fieber, Rückfallfieber und Milzbrand ausschließen. Es ist also den Autoren zuzustimmen, welche eine Virusgenese bevorzugen, wobei von der grippalen Genese schon lange vor der Kenntnis von Viren geschrieben worden ist. Püschel erörterte 1958 die bekannten viralen Encephalitiden, in deren Gruppe er auch den Erreger des Englischen Schweißes vermutete [42].

Mehr auf die pulmonalen Symptome konzentrierte sich Ende der 1990er-Jahre eine englische Arbeitsgruppe, die eine Hantavirus-Infektion als Ursache angab. Als Quelle dieser Infektion setzen sie einen Nagetier-Wirt voraus, von dem das Virus auf Menschen übertragen wurde, von denen es dann direkt von Mensch zu Mensch weiter weitergegeben wurde $[43,44]$.

Es ist offenbar bisher nicht gelungen, aus den Gebeinen von sicheren Opfern des Englischen Schweißes mittels DNA-Analysen den Erreger nachzuweisen [45], wie es bei der Pest möglich war.

Ich glaube, dass wir uns von der Idee verabschieden sollen, der Englische Schweiß müsse sich unbedingt einer bekannten Virusinfektion zuordnen lassen. Wir haben doch seit etwa der Mitte des 20. Jahrhunderts plötzlich auftretende Virusinfektionen kennen gelernt, die als „Emerging Diseases“ zeitlich mehr oder weniger begrenzte epidemische oder pandemische Ausbrüche verursachten. Es seien die MarburgKrankheit, Aids, Ebola, SARS (Severe acute respiratory syndrome), MERS (Middle East respiratory syndrome), Schweine- und Vogel-Influenzen verschiedener Serotypen genannt. Vielleicht gehören der Englische Schweiß und der Schweißfriesel zu den „Emerging Diseases“ ihrer Zeiten.

Interessenkonflikt H. Flamm gibt an, dass kein Interessenkonflikt besteht.

\section{Literatur}

1. Apotheker Paul und Dominicus. Handschrift: Regement vnd Ártzneỷ in dem Englischn Schwais - 1529 - Vnd am lesten Steet für die Brey̋n - Ich noch Zülest für die Pestilentz - Vnd noch am blat ain Cöstlich bewart stückh vom Hanf sam̃en alten Vnd Jüngen Vnd Vergifften sachen. $155 \mathrm{x}$ $200 \mathrm{~mm}$, geheftet, Titelbatt, 59 beschriebene, sieben freien Seiten.

2. KlumpA.Ein kurtz Regiment vnd Consilium für die erschrockenlichen schnellenn kranckheyt, der Englisch schweiss genannt. Freyburgim Breisgau:J. Juliac; 1529.

3. Bocconi T. De Sudore Anglico Disertatio Inauguralis. Ticini Regii: Fusi. 1839.

4. FrankJP. Grundsätze über die Behandlung der Krankheiten des Menschen, zu akademischen Vorlesungen bestimmt. 1 . Theil. Von den Fiebern. § 85. Mannheim: Schwan \& Götz; 1794.

5. Winkle S. Kulturgeschichte der Seuchen. Düsseldorf/ Zürich:Artemis \&Winkler; 1997.

6. Hecker JFC. Der englische Schweiss. Berlin: Th. Chr. Fr. Enslin; 1834.

7. Creighton Ch. A History of Epidemics in Britain. 2. Aufl. London: Franc \& Co. Ltd.; 1965. pp. 237 ff., zit. n. Kühnel A., Jahrb. Landeskunde Niederösterreich, NF, 38. Wien: Selbstverlag d Vereines f Landesk. v NÖ u Wien; 1970. S.339-43.

8. Senf H. Ein kartographischer Beitrag zur Geschichte des Englischen Schweißes. Kyklos Jahrb Gesch Med. 1930;3:283-91.

9. Lemser H. Der Englische Schweiß in seiner Abhängigkeit von Rasse, Boden und Klima.ZHyg. 1937;119:476-504.

10. Brelochs A. Eyn kurtzer gegründter vnderricht/vnnd erklerung einer geschwinden/vnd überscharrpffen seůchten/yetzo von vielen/der Englisch schwayß/aber von den Alten das Pestilentzisch fieber genannt/mit nůtzlicher vnd 
vast trỏstlicher anzeygung/weß sich der mensch vorhin/ oder so er darmit verhafft/mit gutter vnnd ỏrdenlicher regierung in Ertzneyen/auch sunst allen notwendigen stůcken halten solle. Nürenberg: Jobst Gutknecht; 1529.

11. Cordus E. Für die newe/hieuor vnerhǒrte vnd erschrǒcklich tǒdtliche kranckheyt/vnd schnellen todt/die Englisch schweyßsucht genañt/also das ein mensch inn.xxiiij.stunden gesundt vnd todt ist. So yetz in Engellandt/Sachsen/Meichsen/Westphalen ec.vnd zů Cǒln grausamlich regiert/Ein trostlich artznei vnd Regiment. Straßburg: Christian Egenolph; 1529.

12. Kegler C. Ein nutzlichs vnd trǒstlichs Regiment wider die Pestilentz/vnd gifftig Pestilentzisch Feber/die Schweissucht genannt/Vnd sonst mancherley gifftig vnd tǒdlich kranckheit. Durch Casparum Kegler zusammen gebracht/ vernewet/vnd mit viel trǒstlichen Experimenten gebessert/die zuuor heimlich gehalten/vnd an den tag nie gegeben sein/Anno 1529. ausgegangen.2.Auflage.Leipzig:Wolff Gůnter; 1551.

13. Kegeler M. Ein Nůtzliches vnd Trǒstlichs Regiment wider die Pestilentz/vnd gifftig Pestilentzisch Feber/die Schweissucht genant/Vnd sonst mancherley gifftige vnd tǒdtliche Kranckheit. Durch Casparum Kegeler/weilandtzusammen gebracht/Nun aber zum Drittenmal durch seinen Son Melchiorem Kegeler in Druck gegeben. Leipzig: Johan. Rhambaw; 1566.

14. Melbrey H. Ordnung und Regiment deren sich in der Schweyssucht das Englisch Bad genannt zu halten sey. Straßburg: Johann Schott: 1529.

15. Schiller abHerderen J. De peste britannica commentariolus vere aureus. Basel: H. Petrus; 1531, Original abgedruckt in Lit. 17, S. 273-310.

16. Doctores zů Franckfurt, Mentz, Worm̃ vnd Speir. Das aller bewertest vñ kürtzest Regimennt/Für die newe Kranckheyt/die Englisch Schwaißsuchtt genañt/wie mã die yetzunder zů Franckfurt/Mentz/Worm̃s vnd Speir gepraucht. Augsburg: Heinrich Steiner; 1529.

17. Gruner ChG. Scriptores de Sudore Anglico superstites. Hsg. v. Haeser H. Jena: Friedrich Mauk; 1847.

18. Bohdanowicz FX. Die Plag' der Pestilenz im Linz des 16. Jahrhunderts. Histor Jahrbuch d Stadt Linz. Linz: Gutenberg; 1962.S. 105-25.

19. Ulrich F. Das Sanitätswesen und die Volkskrankheiten des 16. Jahrhunderts im Lande ob der Enns. 16. Bericht über das Museum Francisco-Carolinum. Linz: Josef Wimmer; 1856. S. 15-23.

20. Flamm H. Die Geschichte der Staatsarzneikunde, Hygiene, Medizinischen Mikrobiologie, Sozialmedizin und Tierseuchenlehrein Österreich undihrerVertreter. Wien:Verlagder Österreichischen Akademie der Wissenschaften; 2012.

21. C.K. (Christina Klettner). Theriak. Katalog der Niederösterr. Landesausstellung „Kunst des Heilens“. Wien: NÖ Landesmuseum; 1991.S.537.

22. Anonym. Vom Enngelschen Schweis villbewerter stück/ welche geschickt worden sind dem Durchlüchtigen Hochgebornen fürsten vnnd Herrn Her Ludwig Pfaltz Graue bey Reyn Ertztruckseß vnnd Chůrfürst des Heyligenn Römischen Reychs etc. - Item eyn neuwe kranckheit kurtzlich auff gestandenn mit den dryen sprüngen/sollichs mit der hyllff Gottes fưr zůkum̃en wirt euch die artzney jn disem bůchlin auch angezeygtt. Durlach:Valentin Kobian; 1529.

23. Heyrenbach JC. Medicvs svi ipsivs, theoreticvs \& practicvs, sev Exegesis diætetici Regiminis, Vsvs \& Abvsvs Sex Rerum necessarium non Naturalium. Steyr: GeorgMenhardt; 1753.

24. Guarinoni H. Die Grewel der Verwüstung Menschlichen Geschlechts. Ingolstatt: Andreas Angermayr; 1610.
25. Zeiss H. Über Englischen Schweiß und Schweißfriesel in Rußland. Arch Hyg. 1932;107:243-54.

26. Kühnel H. Grosse Seuchen des Mittelalters und der frühen Neuzeit. Katalog der Niederösterr. Landesausstellung „Kunst des Heilens“. Wien: NÖ Landesmuseum; 1991. S. 407-22.

27. Püschel E. Der Englische Schweiß des Jahres 1529 in Deutschland. Sudhofs Arch Gesch Med. 1958;42:161-83.

28. Fuhrmann M. Alt- und Neues Wien, Oder dieser kayserlich- und Ertz-Lands-fürstlichen Residenz-Stadt Chronologisch-undHistorischeBeschreibung. Wien:JohanBaptist Proster; 1739.2. Teil, S. 745.

29. Pez H. Scriptores Rerum Austriacarum Veteres Ac Genuini Quotquot Ex Austriae Vicinariumque Provinciarum Bibliothecis Et Tabulariis, Decumano Labore Perillustratis, AutPrimum In Lucem Vindicari, Aut Ex Mss. Codicibus Auctiores Et Emendatiores Edi Potuerunt. Leipzig: J. F. Gleditschii Filii; 1721. Teil I, Kol.284D-285 B.

30. Mitterdorffer S. Conspectus Historiæ Universitatis Viennensis, ex antiquis, veteribùsque Documentis erutæ. Tom. II, Fol. 140.1724.

31. Haeser H. Lehrbuch der Geschichte der Medicin und der epidemischen Krankheiten. 3. Aufl. Bd. 3. Jena: G. Fischer; 1882.

32. Hecker JFC. Die grossen Volkskrankheiten des Mittelalters. Hsg. v. Hirsch A. Berlin:Th. Chr. Fr. Enslin; 1865.

33. Hirsch A. Die allgemeinen acuten Infectionskrankheiten vom historisch-geographischen Standpunkte. In: Hirsch A, Hrsg. Handbuch der Historisch-geographischen Pathologie. 2. Aufl. Stuttgart: Ferd. Enke; 1881.

34. Schnurrer F. Chronik der Seuchen in Verbindung mit den gleichzeitigen Vorgängen in der physischen Welt und in der Geschichteder Menschen. Bd.2.Tübingen:Ch. F. Osiander; 1825.

35. Klempzen, N.ab. Vom Pommer-Lande und dessen FürstenGeschlecht. Stralsund:Struck; 1771.Zit. n. Lit. 17, S. 442

36. Flamm H. Die ersten Infektions- oder Pest-Ordnungen in den Österreichischen Erzlanden, im Fürstlichen Erzstift Salzburg und im Innviertel im 16. Jahrhundert. Wien:Verlag derÖsterreichischen Akademie der Wissenschaften; 2008.

37. Caius J. A Boke, or Counseill against the Disease commonly called The Sweat, or sweating Sicknesse. London: o. V.; 1552, Original abgedruckt in Lit. 17, S.311-44.

38. Chronicon Norimbergense (Fragment). Zit. n. Lit. 17, S. 447.

39. Weichselbaum A. Ueber Schweissfriesel vom anatomischen, ätiologischen und epidemiologischen Standpunkte. Z. klin. Med. 1907;62:21-50.

40. Nocht B, Paschen E, Hegler C, Hrsg. Jochmanns Lehrbuch der Infektionskrankheiten für Ärzte und Studierende. 2. Aufl. Berlin:Springer; 1924. S.968-76.

41. PatrickA, Roberts RS. A Consideration on the Nature oft the English Sweating Disease. Med Hist. 1965;9:277-9-385-9.

42. Püschel E. Der Englische Schweiß des Jahres 1529 in Deutschland. Sudhofs Arch Gesch Med. 1958;42:161-83.

43. Taviner M, Thwaites G, Gant V. The English Sweating Sickness, 1485-1551: a viral pulmonary disease? Med Hist. 1998;42:96-8.

44. Thwaites G, Taviner M, Gant V. The English sweating sickness, 1485 to 1551. NEnglJ Med. 1997;336:580-2.

45. Wikipedia,Hrsg. EnglischerSchweiß.https://de.wikipedia. org/w/index.php?title=Englischer_Schwei\%C3\%9F\&oldid $=172689703$.Zugegriffen: 28 . Nov. 2018 .

Hinweis des Verlags Der Verlag bleibt in Hinblick auf geografische Zuordnungen und Gebietsbezeichnungen in veröffentlichten Karten und Institutsadressen neutral. 